\title{
Introduction of Learning Visualisations and Metacognitive Support in a Persuadable Open Learner Model
}

\author{
Susan Bull \\ Institute of Education \\ University College London, \\ UK \\ s.bull@ucl.ac.uk.
}

\author{
Clelia Boscolo \\ University of Birmingham, \\ UK \\ c.boscolo@bham.ac. \\ uk
}

\begin{abstract}
This paper describes open learner models as visualisations of learning for learners, with a particular focus on how information about their learning can be used to help them reflect on their skills, identify gaps in their skills, and plan their future learning. We offer an approach that, in addition to providing visualisations of their learning, allows learners to propose changes to their learner model. This aims to help improve the accuracy of the learner model by taking into account student viewpoints on their learning, while also promoting learner reflection on their learning as part of a discussion of the content of their learner model. This aligns well with recent calls for learning analytics for learners. Building on previous research showing that learners will use open learner models, we here investigate their initial reactions to open learner model features to identify the likelihood of uptake in contexts where an open learner model is offered on an optional basis. We focus on university students' perceptions of a range of visualisations and their stated preferences for a facility to view evidence for the learner model data and to propose changes to the values.
\end{abstract}

\section{CCS Concepts}

- Human-centered computing $\rightarrow$ Human computer interaction (HCI); user model, user studies $\rightarrow$ Visualization; Visual analytics; Visualization systems and tools - Applied Computing $\rightarrow$ Education; Interactive learning environments.

\section{Keywords}

Visual Learning Analytics; Open Learner Models; Learning Analytics for Learners; Persuading the Learner Model.

\section{INTRODUCTION}

Visual analytics combine the strengths of people and computers in processing data [25]. With the growth of interest in learning analytics, visualisations and dashboards have been developed for education settings (e.g. $[2 ; 10 ; 19 ; 43])$. There is also growing recognition that, because learning analytics are concerned with learning, they should offer pedagogically useful information [22]. Permission to make digital or hard copies of all or part of this work for personal or classroom use is granted without fee provided that copies are not made or distributed for profit or commercial advantage and that copies bear this notice and the full citation on the first page.

Copyrights for components of this work owned by others than ACM must be honored. Abstracting with credit is permitted. To copy otherwise, or republish, to post on servers or to redistribute to lists, requires prior specific permission and/or a fee. Request permissions from Permissions@acm.org.

LAK '16, April 25-29, 2016, Edinburgh, United Kingdom

(C) 2016 ACM. ISBN 978-1-4503-4190-5/16/04 ...\$15.00

DOI: http://dx.doi.org/10.1145/2883851.2883853

\author{
Matthew Johnson \\ University of Birmingham, \\ UK \\ m.d.johnson.1@bham \\ .ac.uk
}

This information also needs to be actionable, i.e. it has to be able to support decision-making [2]. For example, learning analytics can help teachers to compare activity and performance indicators in large datasets, to allow them to take decisions about their use of particular activities [20]; or social learning analytics dashboards may help teachers better identify learner-learner interactions, which may help them to intervene in cases such as where there are disconnected students, or help them recognise those who have influence over others as indicated by ratings or followers [21].

Learning analytics visualisations can also be helpful for the learners themselves (e.g. $[15 ; 18 ; 21 ; 44])$, and it is this area that is of particular interest in this paper; specifically, open learner models (OLM). The essence of a learner model is a representation of an individual's current state of knowledge, skills, competencies, etc., which is inferred according to their interaction with an educational system [46]. Thus, it is not so much a count of performance or other data as is more common in learning analytics, but it is, indeed, a representation of understanding or learning. It is the learner model that allows an adaptive system to appropriately personalise the interaction to suit the individual learner's needs at the time.

Open learner models are learner models that externalise the inferred learner model contents to the learner (or other user), usually with some kind of visualisation. Often this has the aim of promoting metacognitive activities such as reflection, selfmonitoring and planning (see [3]), and therefore has a similar goal to some of the arguments for learning analytics visualisations to facilitate such activities, e.g. self-directed learning [15] and metacognition [18].

Typically, in learning analytics, traditional visualisation methods have been used in learning dashboards. These include bar charts [20; 23; 36; 38]; pie charts [23; 41]; histograms [27; 41]; radar plots [21]; scatterplots [36]; tables [38]; or timelines [20; 27; 38]. Other examples include networks [21; 41] and tag clouds [41]. As can be seen from the above, often several visualisations are available on a learning dashboard (e.g. [38; 41]).

OLMs often use different visualisation forms than those most commonly found in learning analytics dashboards. For example: skill meters $[6 ; 7 ; 12 ; 17 ; 28 ; 33 ; 45]$, concept maps $[1 ; 17 ; 30 ; 37]$ and hierarchical tree structures $[11 ; 17 ; 24 ; 30]$ are particularly common. Other visualisations as mentioned above for learning analytics, can also be found in open learner models (e.g. tag/word clouds [7; 31] and network visualisations [7]). The overlap between learning analytics visualisations and OLM visualisations is often in the newer visualisation types. As with learning analytics dashboards, some open learner models have multiple visualisations (e.g. [7; 17]). Figures 1 and 2 show examples from the LEA's Box open learner model. 


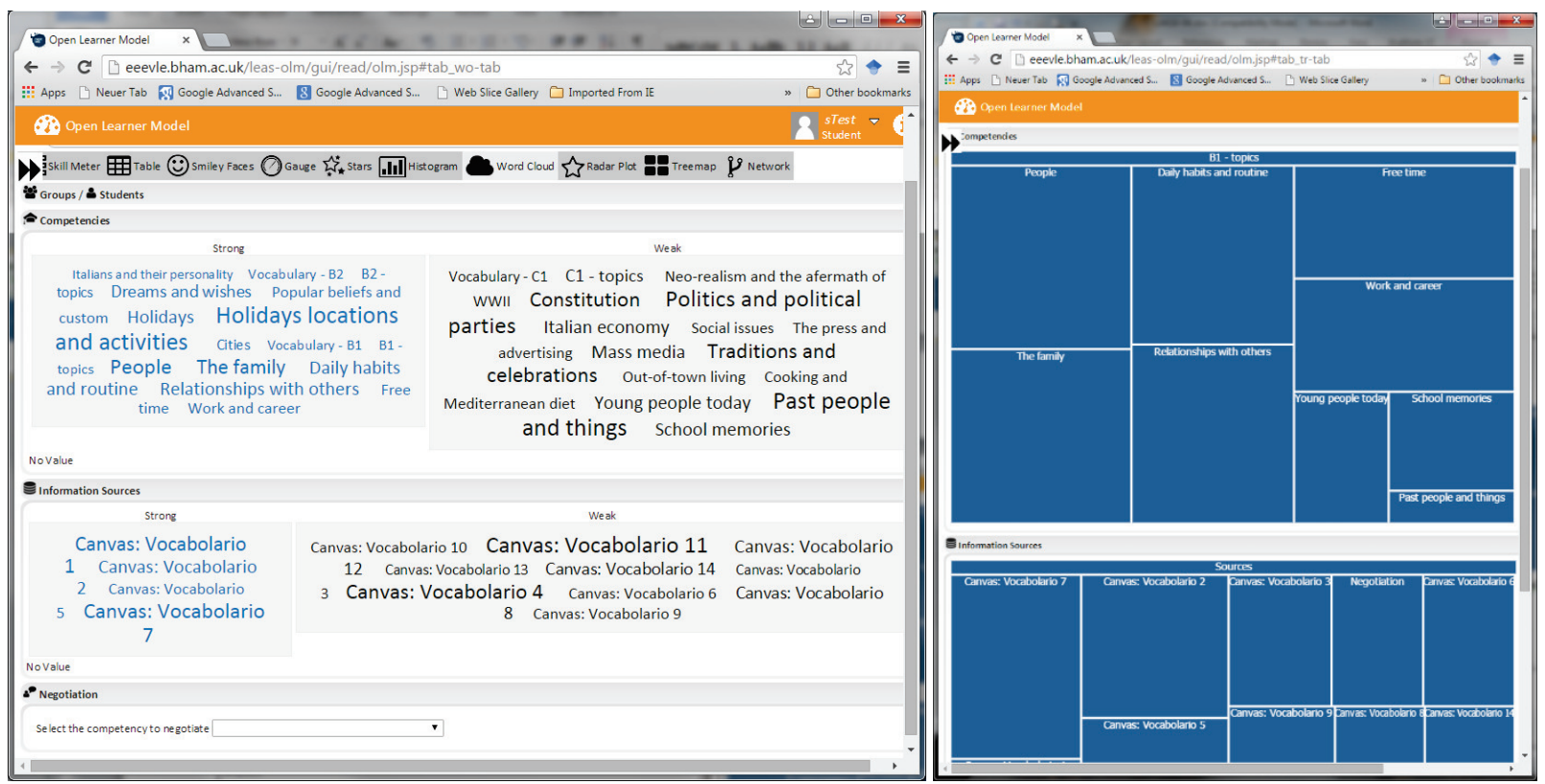

Figure 1: The LEA's Box OLM: word cloud and treemap visualisations.
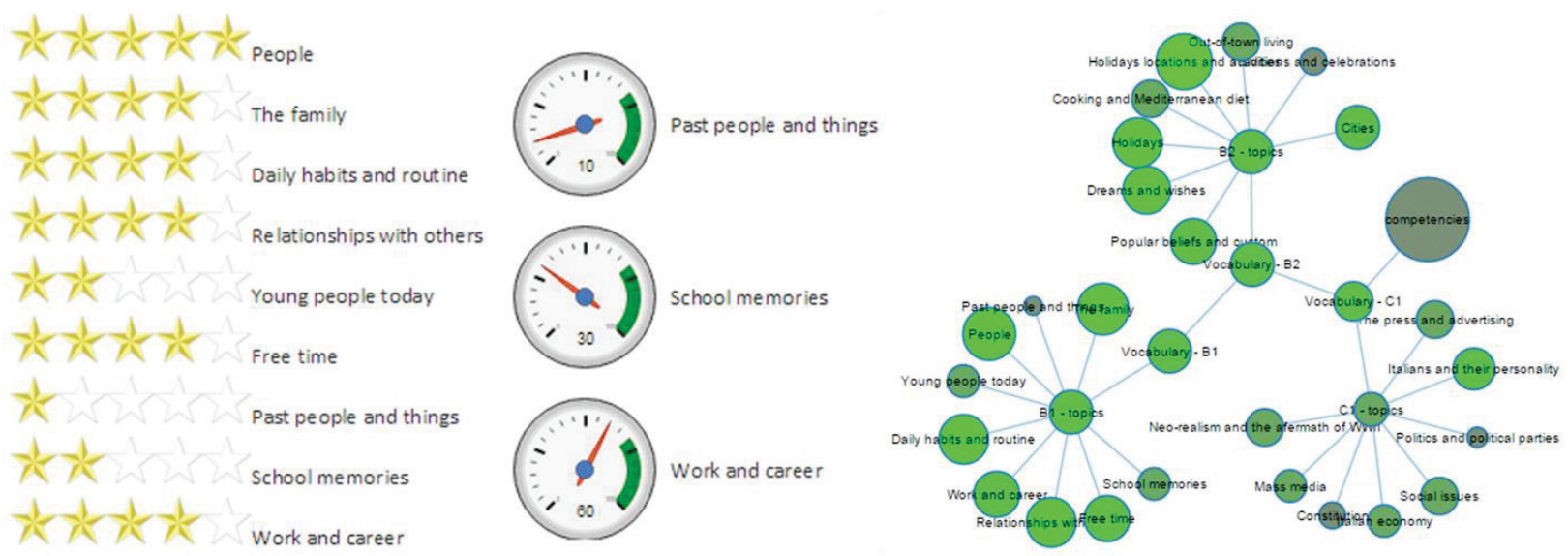

\begin{tabular}{|c|c|c|c|c|c|}
\hline Constitution & - & & & & \\
\hline Politics and political partie & 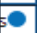 & & & & \\
\hline Italian economy & & - & & & \\
\hline Italians and their personal & $\mathrm{y}$ & & - & & \\
\hline Social issues & & - & & & \\
\hline The press and advertising & & - & & & \\
\hline Mass media & & - & & & \\
\hline Vocabulary - B2 & & & O & & \\
\hline B2-topics & & & 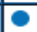 & & \\
\hline Dre ams and wishes & & & & - & \\
\hline
\end{tabular}

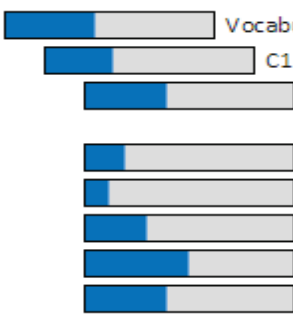

ocabulary - C1

Neo-realism and the aftermath of WWII

(ब)

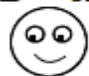

Constitution

Politics and political parties

It alian economy

Italians and the ir personality

Social issues
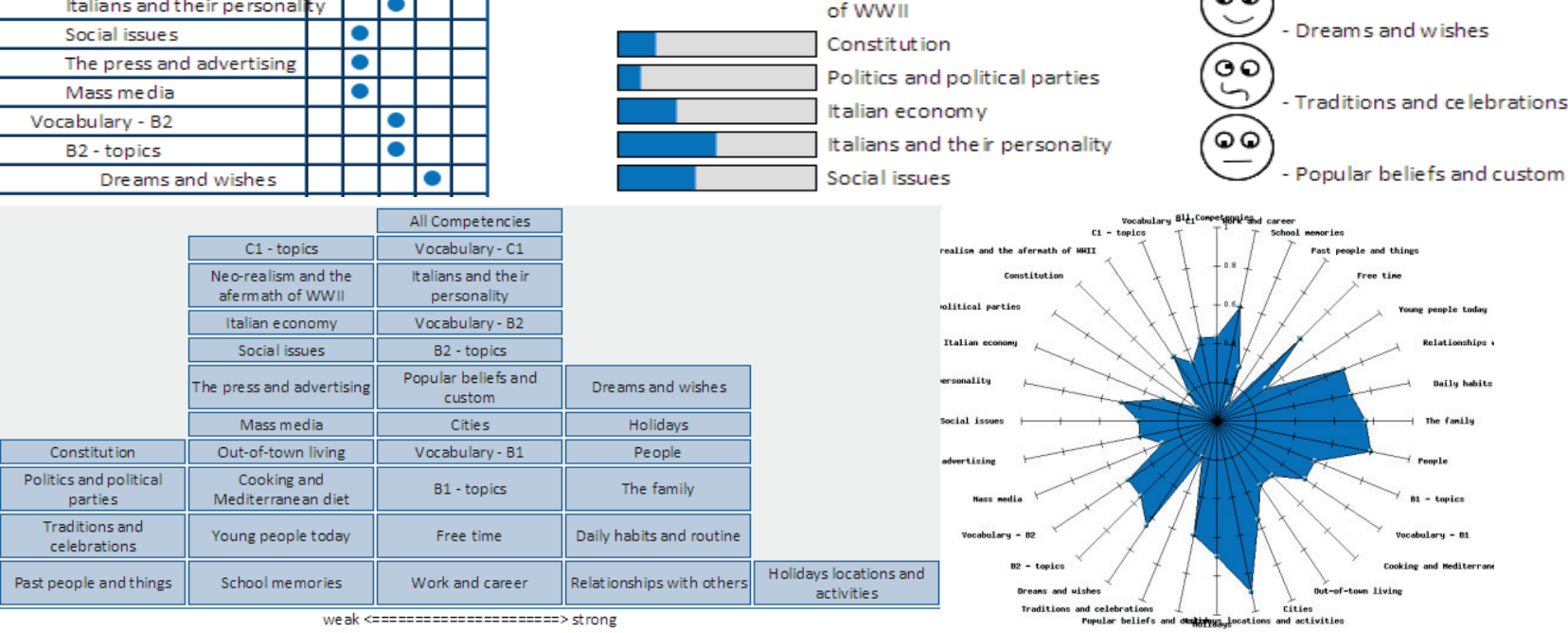

Figure 2: The LEA's Box OLM: stars, gauges, network, table, skill meters, smileys, histogram and radar plot visualisations. 
In addition to allowing users to see the information in their learner model, and in a way that is meaningful and facilitates action, learner models can in some cases also be negotiated (e.g. [4; 16; 26]), where either the learner or the system can initiate discussion to try to resolve any differences between their respective beliefs about the learner's knowledge, and each partner provides evidence or justifications of their viewpoints. Separate learner model representations (for the system's and student's beliefs about the learner's skills) are retained if there is no agreement. Alternatively, some learner models allow attempts at persuasion: a learner can try to persuade the system to change a value in their learner model, providing evidence to convince the system (e.g. [9; $29 ; 40 ; 42]$ ). Only if the system is convinced by this evidence, will it update the learner model to reflect the learner's requested change. While there are similarities between negotiated and persuadable learner models, the main difference is that in the latter, control of the learner model data lies with the system, while negotiated learner models allow parallel representations of student and system beliefs if there is disagreement.

Approaches such as the above allow learners to suggest changes to outdated or inaccurate representations in their learner model, and often also aim to promote learner reflection on their learning, as part of the discussion process [5]. This is possible in OLMs because the visualised data is not simply a count of activity or behavior - which will be an accurate count of instances (e.g. clicks, materials accessed, exercises attempted, performance scores) - but rather, comprises inferences about learning. As stated above, this interaction about the content of the learner model aims to provide a means to improve the accuracy of the model: e.g. if a learner had obtained correct answers through guessing, the learner may try to decrease a value; or if the learner had done some additional reading, they may try to increase a value in their learner model (or, indeed, they may try to decrease it, if on reading they realise that their understanding is not as strong as the representations in their model suggest). Importantly, this discussion process also aims to prompt reflection on learning as learners consider the evidence for the learner model values, and must provide justifications if they attempt to change any value in their model.

In the next section we introduce the LEA's Box (Learning Analytics Toolbox) OLM, which has multiple visualisations and offers a persuasion mechanism. We then describe a study investigating which features university students would expect to use, to help identify useful features for OLM developers, and ways to introduce OLMs in optional settings to encourage uptake. While we already know that students will use an OLM similar to this one [8], we know less about their intentions before they adopt it. This information is also important.

\section{THE LEA's BOX OLM}

Multiple visualisations have previously been suggested to be beneficial in OLMs, to allow users to select the visualisation according to their reason for viewing the learner model and their individual preferences for viewing $[7 ; 30 ; 39 ; 42]$. The LEA's Box OLM has ten visualisations. It also has a discussion facility to allow students to obtain evidence for their learner model data and, if considered appropriate, to try to argue for changes to the values in their model. In this version of the LEA's Box OLM, we take the approach of persuasion, where the student alone can initiate discussion, and if there is no agreed outcome, the model remains unchanged. Future work will develop this into a full negotiation mechanism, hence the appearance of the term "negotiation" in the interface.
In line with some other technology-enhanced learning contexts where learning data from multiple sources is held in the learner model (e.g. $[8 ; 14 ; 32 ; 34])$, the LEA's Box OLM can take data from a range of activities or sources. In our current example, the activities are completed in the course Learning Management System. While the OLM can be used in any subject, we here use the example of language learning, and specifically, vocabulary topics.

\subsection{OLM Visualisations}

Figures 1 and 2 give examples of how the learner model is visualised to learners (based on [7]). Figure 1 shows the word cloud visualisation for a "Test Student", where the larger (blue) text on the left indicates strong areas, with less strong topics in smaller text; and the larger (black) text on the right shows weaker areas, with less weak (but still low) areas in smaller text. The treemap shows the strength of topics by the size of the corresponding squares. These screens also show the quiz names, again with the quizzes that contribute the highest level shown on the left of the word cloud (in blue), and the quizzes with lower levels of mastery on the right (in black text); and the size of the square for a quiz in the treemap indicating that quiz's influence in the learner model. This allows students to see their levels across all vocabulary topics, as well as the specific activities that contributed the data. Figure 2 gives examples of the other visualisations available: stars, gauges, network, table, skill meters, smileys, histogram and radar plot. Skill meters, as indicated above, are common OLM visualisations. Unlike progress bars, commonly used in computer systems, these reflect the current inferred learning state. In LEA's Box we have two versions - the stars which quantise the data into five levels, and the continuous skill meters. The gauge and radar plot also show continuous values. The table, smileys and histogram show discrete values. The treemap and network visualisations use size (and brightness, in the case of the network), to indicate the strength of topics. The treemap allows the learner to click on a cell to view the next layer in the hierarchical structure, while clicking on a node in the network allows the nodes to be expanded or collapsed, to view more or less information. Thus, the different visualisations may be more or less useful depending on the number of areas displayed, and may also be viewed according to individual preferences.

Table 1: LEA's Box OLM visualisation categories.

\begin{tabular}{|l|c|c|c|c|}
\cline { 2 - 5 } \multicolumn{1}{c|}{} & Quantised & Continuous & Structured & Unstructure \\
\hline Skillmeters & & $\times$ & $\times$ & \\
\hline Table & $\times$ & & $\times$ & \\
\hline Smileys & $\times$ & & $\times$ & \\
\hline Stars & $\times$ & & $\times$ & \\
\hline Gauges & & $\times$ & $\times$ & \\
\hline Word cloud & & $\times$ & & $\times$ \\
\hline Histogram & $\times$ & & & $\times$ \\
\hline Radar plot & & $\times$ & & $\times$ \\
\hline Treemap & & $\times$ & $\times$ & \\
\hline Network & $\times$ & & $\times$ & \\
\hline
\end{tabular}


Table 1 gives an overview of some of the features of the visualisations. As stated above, some visualisations are quantised on a five point scale, while others use a continuous scale. Most visualisations also indicate the structure of the domain. Thus, using those visualisations, it is possible to see a topic parent or child, if applicable.

\subsection{OLM Persuasion}

After viewing their OLM as in Figure 1 or 2, if a student is unsure about the accuracy of a value, or if they disagree with it, they can opt to try to change it through discussion (see bottom of the word cloud screen in Figure 1). The persuasion workflow is shown in Figure 3. When discussion of a given vocabulary topic is initiated by the student, the student's current level for this topic is displayed as a statement. The student can then either request evidence or give a self-assessment. This is shown in Figure 4.

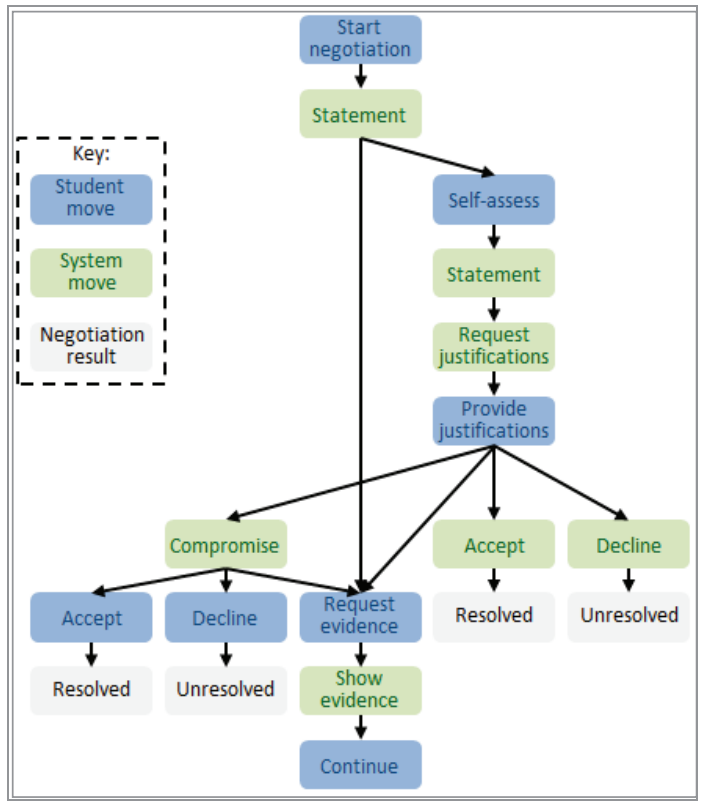

Figure 3: Discussion workflow.

The move "request evidence" (right, middle) is available to the learner during all persuasion steps. The evidence explains how the current level is calculated for the area being discussed (Figure 5). It takes into account all pieces of evidence that are directly associated with this, as well as any sub-topics. A piece of evidence can, for example, be a score in an exam or a quiz, a teacher assessment, an activity in another system that may or may not model the learner's knowledge, or the result of a past resolved discussion of the topic. Each piece of evidence has a weight (based on [7]): the more recent a piece of evidence, the higher its weight (unless the relative weights have been changed by the teacher). In this example there are three pieces of evidence.

The student's self-assessment is followed by a statement from the system that reminds the learner of their current level and selfassessment. The system then requests justifications before it will increase or decrease the student's level for this topic in their learner model, to match their self-assessment (Figure 5). Depending on the student's justification, current level and selfassessment, the system uses the discussion parameters defined by the instructor (Figure 6) to accept or decline the student's selfassessment, or to propose a compromise between the student's self-assessment and the current representation of their level in their learner model. If a self-assessment or a compromise is accepted, the discussion ends because the system has been persuaded, and the model is updated with a level that both the student and the system accept. This agreed level becomes a new piece of evidence for this topic, with "negotiation" noted as the source of evidence and the student as contributor. However, if a self-assessment or a compromise is declined, the discussion ends, but the model is not changed.

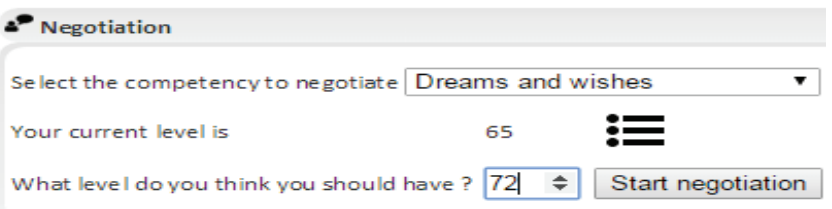

Figure 4: System statement and student self-assessment.

In the example in Figure 6, the teacher has defined all justifications to have equal weight (5), with justifications for upward changes having a positive value, and justifications for downward changes having a negative value. In principle, the same phrase could be used both positively and negatively. For example, a learner could consider themselves to be stronger or weaker than reflected in their learner model, for a particular area. They might therefore give the reason 'I have done an exercise' as justification for a change in either direction, if this option has been defined by the instructor for both cases. This is easily done, since justifications with positive associated values only show (as in Figure 5) for selection when a learner tries to increase a value in their learner model, and justifications with negative associated values are only available if a learner tries to decrease a value.

The maximum threshold defined by the instructor (Figure 6) is the maximum increase allowed to a learner model value during persuasion, without the system requiring further information; and the minimum threshold is the maximum decrease allowed without requiring justification. Thus, in this example, a self-assessment of +10 or -10 will be accepted; a request to change a value by more than this will not be automatically accepted. The minimum number of pieces of evidence between negotiations can be defined to ensure that students cannot simply change a learner model value multiple times for a topic, without additional evidence being collected from another source. In this example, two further pieces of evidence for a topic are required before a new discussion of the value can take place. The minimum time between negotiations has a similar purpose. It can be set to no minimum; 15 minutes (as here); 30 minutes; 1 hour; 1 day; or 1 week (future work will allow instructors to define other values). This is another method to ensure that a student cannot easily change values without appropriate consideration.

When a student proposes a new value, the system may offer a compromise if the proposed value is beyond the given threshold. They will be required to provide one or more justifications, and the values defined for these (here +5 or -5 ) will be used to calculate the compromise value. This value must fall within the instructor's threshold (here 10, which can include two justifications as all combinations of two justifications will total 10); but will be as close to the student's proposed value as is permitted. This implementation of persuasion differs from previous work in that usually a student can demonstrate their skills by answering questions selected to verify their claims (e.g. $[9 ; 29 ; 40 ; 42])$. Because LEA's Box has multiple data sources and is domain- independent, all justifications are currently in the form of statements predefined by the teacher. 
Negotiation

Your are negotiating the competency Dreams and wishes. Your current level is 65.

System evidence for the competency Dreams and wishes

\begin{tabular}{|ccccc|}
\hline Time & Contributor & Source & Value & Weight \\
$2015-10-27$ at $10: 56$ & Boscolo Cle lia (teacher) & Canvas: Vocabolario 2 & 0.72 & 0.41 \\
$2015-10-24$ at $15: 34$ & Boscolo Cle lia (teacher) & Canvas: Vocabolario 4 & 0.57 & 0.33 \\
$2015-10-21$ at $11: 57$ & Test Student (student) & Negotiation & 0.65 & 0.26 \\
\hline
\end{tabular}

You think your level should be 72 .

Could you please tell me why?

Just ification:

\begin{tabular}{|l|l}
\hline I have done some homework Comments: \\
I knew the answer but spelt it wrong $\mathbf{v}$ Comments:
\end{tabular}

Just ification:

Remove justific ation

Continue

Add justific ation

Figure 5: Justifying a change to the learner model.

In future work students may also be directed back to specific activities in specific data sources, allowing evidence of their skills to be demonstrated, as in other approaches to persuading and negotiating the learner model. The two approaches will then be used together.

Table 2 describes the possible discussion moves for student and system, with examples. (Except for self-assess, future work on negotiation will implement the currently missing cells.)

\begin{tabular}{|c|c|}
\hline \multicolumn{2}{|l|}{ Negotiation parameters } \\
\hline \multicolumn{2}{|l|}{ Maximun incre ase threshold 10} \\
\hline \multicolumn{2}{|l|}{ Maximun decrease threshold 10} \\
\hline \multicolumn{2}{|c|}{ Minimum number of other kind of evidence between two negotiations 2} \\
\hline \multicolumn{2}{|l|}{ Minimum time between two ne gotiations 15 minutes $\mathbf{v}$} \\
\hline \multicolumn{2}{|l|}{ Student list of justifications } \\
\hline Justification label: I have done some homework & We ight: 5 \\
\hline Justification label: I have had a class on this & We ight: 5 \\
\hline Justification label: I have done some reading & We ight: 5 \\
\hline Justification label: I have done some exercises & We ight: 5 \\
\hline Justification label: I knew the answer but spelt it wrong & We ight: 5 \\
\hline Justification label: Other (please comment) & We ight: 5 \\
\hline Justification label: I got answers right by guessing & We ight: -5 \\
\hline Justification label: I have forgotten this & We ight: -5 \\
\hline Justification label: Other (please comment) & We ight: -5 \\
\hline
\end{tabular}

Figure 6: Defining the justification options.
Table 2: Negotiation moves and examples.

\begin{tabular}{|c|c|c|}
\hline & Student & System \\
\hline Initiate discussion & $\begin{array}{l}\text { Select a topic to } \\
\text { discuss. }\end{array}$ & X \\
\hline Accept/agree & $\begin{array}{l}\text { Accept a compromise. } \\
\text { Agree with the } \\
\text { evidence provided. }\end{array}$ & $\begin{array}{l}\text { Accept a compromise. } \\
\text { Agree with the student's } \\
\text { justifications. }\end{array}$ \\
\hline Decline & $\begin{array}{l}\text { Decline a compromise } \\
\text { proposed by the system. }\end{array}$ & $\begin{array}{l}\text { "Your last negotiation for } \\
\text { this is too recent to allow a } \\
\text { new negotiation." }\end{array}$ \\
\hline Compromise & X & $\begin{array}{l}\text { Propose a compromise } \\
\text { between the current value } \\
\text { and the student's self- } \\
\text { assessment. }\end{array}$ \\
\hline $\begin{array}{l}\text { Request evidence } \\
\text { Request } \\
\text { justifications }\end{array}$ & $\begin{array}{l}\text { Request evidence for } \\
\text { the current value. }\end{array}$ & $\begin{array}{l}\text { Request justifications for a } \\
\text { self-assessment. }\end{array}$ \\
\hline $\begin{array}{l}\text { Provide evidence } \\
\text { Provide } \\
\text { justifications }\end{array}$ & $\begin{array}{l}\text { "I have done some } \\
\text { homework." } \\
\text { "I have had a class." } \\
\text { "I have done some } \\
\text { reading." }\end{array}$ & $\begin{array}{l}\text { "Your level in vocabulary } \\
\text { is } 72 \text { and this is a sub-topic } \\
\text { of Italian." }\end{array}$ \\
\hline Self-assess & $\begin{array}{l}\text { "I think my level should } \\
\text { be } 80 . "\end{array}$ & X \\
\hline $\begin{array}{l}\text { Challenge } \\
\text { evidence }\end{array}$ & X & X \\
\hline Statement & X & $\begin{array}{l}\text { "Your level for vocabulary } \\
\text { is } 75 \text { and you think it } \\
\text { should be } 80 . "\end{array}$ \\
\hline
\end{tabular}




\section{STUDENT PERCEPTIONS}

The LEA's Box OLM was introduced in a final year module on Italian language, in the Department of Modern Languages at the University of Birmingham, UK. The Italian course uses a suite of over 340 formative assessment quizzes in the institution's chosen Learning Management System. There are no summative marks associated with these activities. The quizzes cover a variety of skills: grammar, vocabulary, reading, listening, etc. In this study we used the area of 'vocabulary'. The vocabulary quizzes are mapped onto the Common European Framework of Reference for Languages (CEFR) [13]. For example, for vocabulary, 26 topics are covered in 14 quizzes. The vocabulary topics and quizzes are linked to three of the CEFR levels (B1, B2, C1) on the basis of range and complexity of topic, as appropriate for the participants (Figure 7).

\section{Vocabulary range}

Vocabulary for everyday life (B1)

Varied vocabulary for specialism and general topics (B2)

Broad lexical repertoire, idioms and colloquialisms (C1)

Vocabulary control

Control of elementary vocabulary (B1)

Ability to communicate well (B2)

Extensive vocabulary control $(\mathrm{C} 1)$

Example vocabulary topics and levels

B1: people, the family, past people and things

B2: traditions and celebrations, cities, out-of-town living

$\mathrm{C} 1$ : politics and political parties, Italian economy, social issues

Figure 7: CEFR levels and examples for vocabulary.

The LEA's Box OLM was introduced to help overcome the problem of use of the quizzes not peaking until the exam preparation period, arguably not the best time to practise and learn vocabulary. The LEA's Box OLM offers an overarching context/environment for students' learning of Italian vocabulary, and a more meaningful way of working with the quizzes, since it allows students to visualise their progress throughout their study and to contextualise this progress in the various aspects of their lexical competence. The opportunity to discuss their levels is seen as an excellent way for students to engage with their learning process, take responsibility for it and also be empowered by it.

In this study we investigate the students' intentions towards using the LEA's Box OLM, as initial perceptions are likely to influence whether students who are completing activities on a formative basis only, proceed to use an environment such as the LEA's Box OLM.

\subsection{Participants, Materials and Methods}

Participants were 25 volunteers in their final year of an undergraduate degree in Modern Languages, who were taking a course in Italian language (see above). They received a demo of the LEA's Box OLM using a "Test Student" account, and an explanation of how the OLM could be used to further explore quiz outcomes with reference to CEFR. They were advised that their expected levels for the current stage of the course were already entered into their OLM, but that their subsequent quiz results may move their levels for the various topic areas and corresponding competences.

Questionnaires were administered to identify participants' anticipated use of OLM features, with items requiring responses on a five point scale: strongly agree (5), agree (4), neutral (3), disagree (2), strongly disagree (1). "Strongly agree" and "agree" are combined in the analysis, as these indicate positive responses. However, the Figures show "strongly agree" and "agree" separately, to provide further detail. There were 10 questionnaire items addressing whether each of the visualisations were likely to be used; 5 relating to how participants expected to use the visualisations; and 6 items referring to their expectations about their use of the persuasion mechanism (referred to in the questionnaires as "negotiation" to be consistent with the terms in the interface).

\subsection{Results}

Figure 8 shows participants' stated intentions for using each of the visualisations. The skill meters are anticipated to be the most likely used, followed by the table and stars. The radar plot and treemap are expected to be least used. Most students indicated that they intend to use several visualisations: mean 3.84 visualisations; median 4; range $0-10$. Table 3 shows the breakdown for expected use of structured/unstructured and quantised/continuous visualisations, a split between students opting for structured only and both, with none expecting to use only unstructured visualisations; and 22 of the 25 participants expecting to use both quantised and continuous visualisations, 1 anticipating using only continuous, and 1 , only quantised.

Figure 9 shows participants' stated expected purposes for accessing the OLM visualisations, and Table 4 shows the mean, median and range values. All purposes (comparing topics, planning, reflection, identifying relative strengths and gaps) are expected to be highly relevant. Table 5 provides further breakdown: 23 of the 25 students gave positive responses for all four purposes of viewing their learner model; 1 gave positive responses for 3 purposes (omitting the reflection option); and 1 indicated that they would use the OLM for only one of the given purposes (planning).

Figure 10 shows participants' expectations regarding their use of the discussion component of the LEA's Box OLM. 23 of the 25 students claim that they would want to view the evidence for values when they disagree with them; and 24 , when they agree with the values. 19 expect to discuss values when they disagree with them; and 14, when they agree. 16 stated that they wish to explain their viewpoint (justify their self-assessments) when they disagree with values; and 13, when they agree. Table 6 gives the mean, median and range values. While some values are lower, the medians show that most participants expect to engage in discussion with the system, regardless of whether they agree or disagree with the values shown in the OLM.

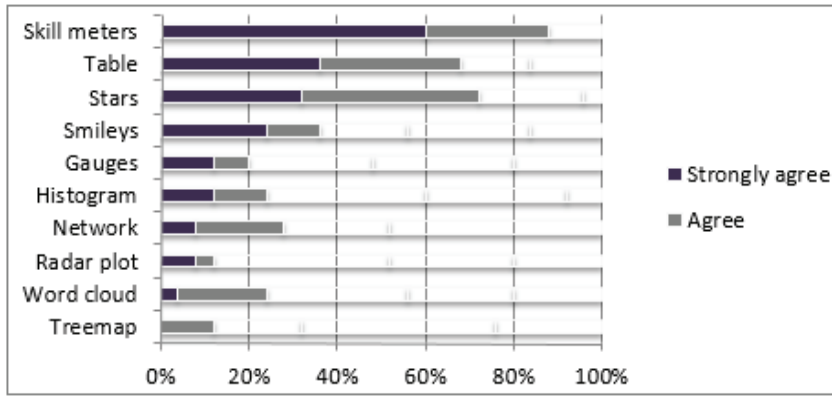

Figure 8: Students' stated choice of visualisations.

Table 3: Expected use of visualisation types.

\begin{tabular}{|c|c|c|}
\hline Structured & Unstructured & Structured and Unstructured \\
\hline 13 & 0 & 11 \\
\hline Quantised & Continuous & Quantised and Continuous \\
\hline 1 & 1 & 22 \\
\hline
\end{tabular}




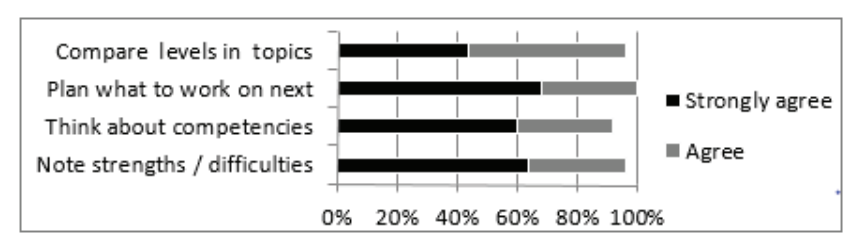

Figure 9: Students' stated purposes for viewing the OLM.

Table 6 shows a high expectation for viewing evidence, but while still positive, less high for discussing values and explaining one's point of view. Figure 11 considers the latter two, with reference to the number of visualisations used. The 3 participants who expect to use 7 or more visualisations also intend to engage more in discussion. A proportionally higher number of students who expect to use only two visualisations, also expect to engage less in attempting to change values or explain their viewpoint.

Table 4: Students' stated purposes for viewing the OLM.

\begin{tabular}{|l|c|c|c|}
\hline Purposes & Mean & Median & Range \\
\hline Compare levels in topics & 4.4 & 4 & $3-5$ \\
\hline Plan & 4.68 & 5 & $4-5$ \\
\hline Think about competencies & 4.52 & 5 & $2-5$ \\
\hline Identify strengths / difficulties & 4.6 & 5 & $3-5$ \\
\hline
\end{tabular}

Table 5: Number of purposes for viewing the OLM.

\begin{tabular}{|l|c|c|c|c|}
\hline & $\begin{array}{c}\text { Four } \\
\text { purposes }\end{array}$ & $\begin{array}{c}\text { Three } \\
\text { purposes }\end{array}$ & $\begin{array}{c}\text { Two } \\
\text { purposes }\end{array}$ & $\begin{array}{c}\text { One } \\
\text { purpose }\end{array}$ \\
\hline Students & 23 & 1 & 0 & 1 \\
\hline
\end{tabular}

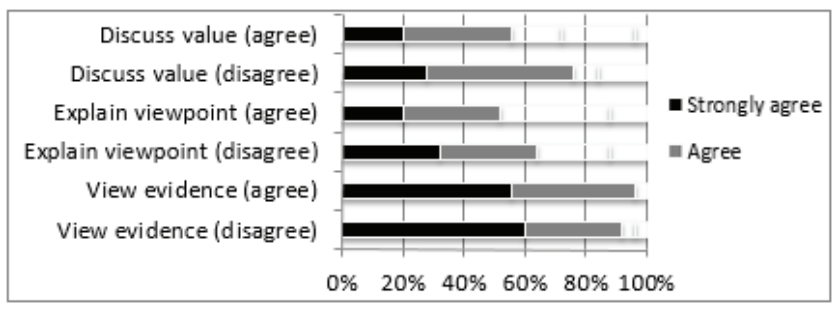

Figure 10: Students' expectations for using discussion feature.
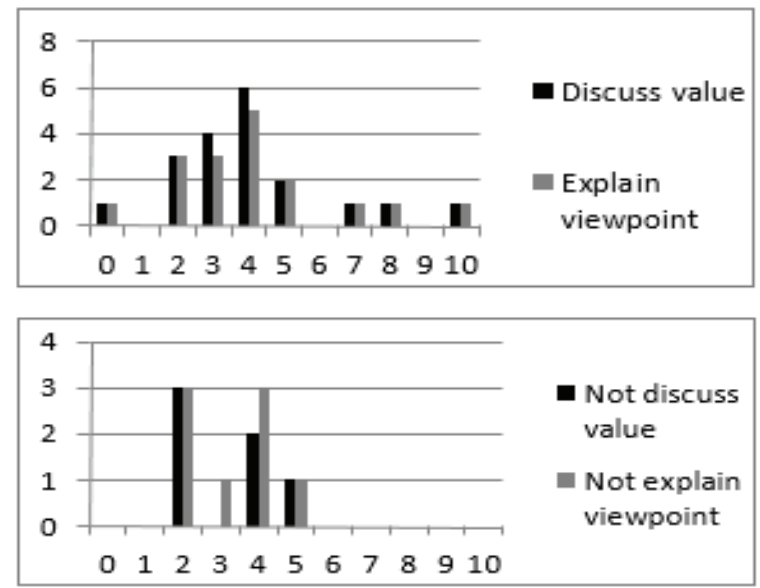

$\mathrm{x}$ - number of visualisations; $\mathrm{y}$ - number of students

Figure 11: Discussing, explaining (upper); not discussing, not explaining (lower).
Table 6: Students' expectations for using discussion feature.

\begin{tabular}{|l|c|c|c|}
\hline Discussion Components & Mean & Median & Range \\
\hline Discuss value (agree) & 3.44 & 4 & $1-5$ \\
\hline Discuss value (disagree) & 3.88 & 4 & $2-5$ \\
\hline Explain viewpoint (agree) & 3.6 & 4 & $2-5$ \\
\hline Explain viewpoint (disagree) & 3.84 & 4 & $2-5$ \\
\hline View evidence (agree) & 4.4 & 5 & $2-5$ \\
\hline View evidence (disagree) & 4.48 & 5 & $2-5$ \\
\hline
\end{tabular}

\subsection{Discussion}

As shown in Figure 8, participants anticipated that they would use the simpler skill meters, table and stars, rather than what may be considered more complex visualisations such as radar plot, word cloud and treemap. Most expected to use multiple visualisations. While we have already seen that most of these visualisations will be used by university students in practice [8], identifying that students would consider some visualisations beneficial before they use an OLM on a voluntary basis leads us to be more confident that they might take the first steps also in contexts in which there is no support for their use of the technology, and in a subject that is not related to technology (in contrast, for example, to [8]). Even if their predictions about their use of the technology do not match how they subsequently use it (see [35]), their expectations of the utility of certain visualisations might motivate them to initially engage with the OLM.

As previously stated, skill meters are amongst the most common learner model visualisation, and it appears that this and similar displays are also considered likely to be beneficial by a large proportion of students before thy use an OLM. Therefore, while there might be a strong case for using complex visualisations: for example, where extensive relationships between different parts of the domain need to be understood (as is perhaps easier with the network view), or expertise across areas of a curriculum should be easily identifiable (as facilitated by the radar plot), inclusion of a simpler visualisation might help engage students initially. It could be argued that our participants had limited experience of the visualisations available, and that for this reason they preferred the simpler visualisations. However, this is the same situation as they faced before first using the OLM on an optional basis. Therefore, our first recommendation to OLM developers is:

1. As well as any visualisations that are particularly relevant to the specific context, include simpler visualisations such as skill meters or similar displays to help students identify a visualisation they can envisage using.

We also found that most students expected to use multiple visualisations. This has also been observed in practice $[6 ; 8 ; 30$; 42], and because students anticipated this also before using the OLM, we recommend:

2. Offer multiple learning visualisations in an OLM to allow students to identify a range of options that they consider suitable.

In cases where specific visualisations are likely to be most appropriate, their use can still be encouraged when students access the OLM.

Table 3 showed that there were no participants who expected to use only unstructured visualisations, with quite an equal split between expected use of structured visualisations only, and both 
structured and unstructured views. We do not know from this data whether the fact that some visualisations were structured, contributed to the preferences suggested for them. However, until this has been investigated further, to facilitate awareness of competency, topic or other structures, we suggest to:

\section{Offer at least one structured visualisation in an OLM.}

We also found that 23 of the 25 participants expected to use both quantised and continuous visualisations. However, since this distinction may be difficult to determine without actual use of the OLM, and because half the visualisations are quantised, and half continuous, we do not draw any conclusions at this stage. However, we suggest this as a feature for further investigation.

Figure 9, Table 4 and Table 5 show participants' stated intentions regarding how they expect to use the visualisations. Nearly all (24) want to use them to help identify their strengths and difficulties; 23 , to support reflection (here defined as "think about competencies"); all 25 stated that they expected to use the visualisations to plan what to work on next; and 24 stated that they wish to compare their levels across the topics. This indicates that the participants view the OLM as a potentially useful support for metacognitive activities, which have long been amongst the main purposes of OLMs (see [3]), and now increasingly noted as important in learning analytics visualisations $[15 ; 18]$. We do not know whether our participants recognised these benefits because we asked about them specifically. We would hope that they would identify this in any case, but to be sure we give the perhaps rather obvious reminder:

4. Explain how an OLM can support metacognition and selfregulated learning to ensure that learners are aware of this purpose.

In line with other research suggesting the utility of providing evidence for learner model values (eg [24]), Figure 10 and Table 6 indicate that participants are keen to see the evidence for the data in their OLM, regardless of whether they agree or disagree with the values. This may be related to their keenness to reflect on their learning, as discussed above - they may view the evidence as a support for their self-directed learning. We therefore recommend to:

5. Offer evidence for learner model values, as a means to facilitate self-monitoring, reflection, planning, etc.

Most participants also stated that they wanted to explain their point of view to the system: around two thirds of the participants when they disagree with a value, and about half also if they agree with it. This further supports our suggestion that students may view the OLM as a useful tool to support metacognition. Based on this, we suggest to:

6. Offer provision for learners to justify their own viewpoints on their understanding, skills, etc., as a means to further prompt metacognitive processes, even if an open learner model does not have a persuade or negotiate facility.

This is further supported by participants' interest in discussing the learner model values: 19 stated that they would wish to discuss a value if they disagreed with it, while 14 would like to do so also if they agreed with it. It appears that some perceive they would benefit from such discussion regardless of whether they aim to change a value. We therefore propose:

7. Allow students to discuss the contents of their learner model with the system if this is feasible in the context of use (i.e. if the learner modelling is sufficient to be able to support this).
Given that we have presented results on both visualisations and learner model discussion options, we also compared the number of visualisations expected to be used, with whether participants anticipated discussing and explaining their learner model. (We omitted the options relating to viewing evidence, as these applied to all participants.) The 3 students who anticipated using a very high number of visualisations also intended to engage in the metacognitive purposes for viewing the learner model. However, this may simply reflect the fact that they wish to make full use of the support available. Conversely, students who did not expect to engage in any of the metacognitive activities associated with the OLM, were proportionally more likely to use only two visualisations. However, the numbers are quite low. We therefore do not conclude anything specific in relation to this, but rather, await additional results.

Our original purpose was to investigate the extent to which students anticipate using different features of an OLM in a formative assessment setting, where there are no scheduled sessions for use of the OLM. The aim was to be able to recommend what to consider when developing and first deploying an OLM amongst a group such as this. One aspect of interest is the persuade feature, that we aim to develop into full negotiation (i.e. where student and system will have equal power, and the same moves will be available to each). We found that most students would want to discuss their OLM values, explain their viewpoints and, especially, view evidence for the learner model values. This often appears to be the case even if students agree with the representations in their model. We therefore broaden our initial goal, and suggest that features that aim primarily to support persuasion or negotiation, may also facilitate metacognition more generally. This is nicely in line with the aim of OLMs to facilitate metacognitive activities [3], and with the call for learning analytics visualisations to be pedagogically useful [22], actionable [2], and to support metacognition [18] and self-directed learning [15]. It also offers further support for long-standing recommendations to provide evidence for learner model values also in OLMs that are not persuadable or negotiable [24].

A limitation of this study is that participants had not yet used the OLM. However, it was also precisely this stage that we wished to investigate. Even though they had not yet had the opportunity to try out the OLM themselves, they appeared to be keen to engage with it. It is important that students perceive benefit if they are to take up a new tool that is not part of their summative assessment, and for which there is little or no time available to support its use. We have therefore made a few recommendations or suggestions for what to include in an OLM or OLM introduction, that might help students recognise the likely benefits, and lead them to engage and then experience these, in contexts where there are no structured sessions and use of the OLM is optional. While we here focused in particular on OLMs, some of the points may also be applicable in other types of learning analytics visualisations designed for students. Our findings should also be followed up with a larger group of participants.

\section{SUMMARY AND CONCLUSIONS}

This paper has presented the LEA's Box OLM, which offers 10 visualisations, and the possibility for students to try to persuade the system to change any learner model values that they disagree with. Our aim was to step back from the use data as has been reported previously, to consider learner perceptions at the time of introduction of an OLM. We found that, in a university setting with no scheduled sessions or support for using the OLM, and where there was no summative assessment associated with the 
activities that would provide the data, students were nevertheless keen to use it to support their learning. Most stated that they intended to use a combination of visualisations, and also that they expected to engage in the metacognitive aspects of the OLM. In particular, students reported that they wanted to be able to view the evidence for OLM values, regardless of whether they would want to try to change those values. We therefore extended our scope to suggest not only that the processes of persuading a system to change a value in an OLM might be beneficial to learning, but also that inclusion of such features in OLMs that do not allow students to try to change values, may also be able to facilitate metacognitive activities.

Based on this initial study, we have made several recommendations or suggestions regarding introduction of, and features of an OLM, for those deploying OLMs and for OLM developers. Future work will compare these initial perceptions to actual usage based on questionnaires and log data, to determine whether use remains in line with the initial expectations. If there is a difference it will be important for future research to consider both initial perceptions and subsequent use, to ensure that students in contexts such as ours will anticipate sufficient benefit to initially engage with the OLM. Subsequent use will then help identify which features are most used and most useful as a learning support. Taken together, this information will help us to design and introduce OLMs that will be used and be useful in practice.

\section{ACKNOWLEDGEMENT}

This project is supported by the European Commission under the Information Society Technology priority FP7 for R\&D, contract 619762 LEA's Box. This document does not represent the opinion of the European Commission and the European Commission is not responsible for any use that might be made of its contents.

\section{REFERENCES}

[1] Ahmad, N., \& Bull, S. (2009). Learner trust in learner model externalisations. In V. Dimitrova, R. Mizoguchi, B. du Boulay, A. Graesser (Ed.), Artificial intelligence in education, Amsterdam: IOS Press, 617-619.

[2] Brown, M. (2012). Learning analytics: Moving from concept to practice, EDUCAUSE Learning Initiative, 1-5.

[3] Bull, S. \& Kay, J. (2013). Open Learner Models as Drivers for Metacognitive Processes, in R. Azevedo \& V. Aleven (eds), International Handbook of Metacognition and Learning Technologies, Springer, New York, 349-365. DOI: 10.1007/978-1-4419-5546-3_23

[4] Bull, S. \& Pain, H. (1995). 'Did I Say What I Think I Said, And Do You Agree With Me?': Inspecting and Questioning the Student Model, in J. Greer (ed), Proceedings of World Conference on Artificial Intelligence and Education, AACE, Charlottesvville VA, 501-508.

[5] Bull, S. (in press). Negotiated Learner Modelling to Maintain Today's Learner Models, Research and Practice in Technology Enhanced Learning.

[6] Bull, S., Jackson, T. J., \& Lancaster, M. J. (2010). Students' interest in their misconceptions in first-year electrical circuits and mathematics courses. International Journal of Electrical Engineering Education, 47(3), 307-318. DOI: 10.7227/ijeee.47.3.6

[7] Bull, S., Johnson, M. D., Masci, D., \& \& Biel, C. (in press). Integrating and visualising diagnostic information for the benefit of learning. In P. Reimann, S. Bull, M. KickmeierRust, R.K. Vatrapu \& B. Wasson (Ed.), Measuring and visualizing learning in the information-rich classroom, Routledge/Taylor and Francis.

[8] Bull, S., Johnson, M.D., Alotaibi, M., Byrne, W. \& Cierniak, G. (2013). Visualising Multiple Data Sources in an Independent Open Learner Model, in H.C. Lane, K. Yacef, J. Mostow \& P. Pavlik (eds), Artificial Intelligence in Education, Springer-Verlag, Berlin Heidelberg, 199-208. DOI: $10.1007 / 978-3-642-39112-521$

[9] Bull, S., Mabbott, A. \& Abu-Issa, A. (2007). UMPTEEN: Named and Anonymous Learner Model Access for Instructors and Peers, Int. Journal of Artificial Intelligence in Education 17(3), 227-253.

[10] Charleer, S., Klerkx, J. \& Duval, E. (2014). Learning dashboards. Journal of Learning Analytics, 1(3), 199-202.

[11] Conejo, R., Trella, M., Cruces, I., \& Garcia, R. (2011). INGRID: A web service tool for hierarchical open learner model visualization. UMAP 2011 Adjunct Poster Proceedings, 406-409. DOI:10.1007/978-3-642-28509-7_38

[12] Corbett, A. T., \& Bhatnagar, A. (1997). Student modeling in the ACT programming tutor: adjusting a procedural learning model with declarative knowledge. User Modeling, 243-254. DOI: 10.1007/978-3-7091-2670-7_25

[13] Council of Europe (nd). The Common European Framework of Reference for Languages: Learning, Teaching, Assessment, http://www.coe.int/t/dg4/linguistic/Source/ Framework_EN.pdf. Accessed 16 October 2015.

[14] Cruces, I., Trella, M., Conejo, R. \& Galvez J. (2010). Student Modeling Services for Hybrid Web Applications, International Workshop on Architectures and Building Blocks of Web-Based User-Adaptive Systems, http://ceurws.org/Vol-609/paper1.pdf.

[15] Dawson, S., Macfadyen, L., Risko, E. F., Foulsham, T., \& Kingstone, A. (2012). Using technology to encourage selfdirected learning: The collaborative lecture annotation system. Proceedings of Ascilite, Wellington, New Zealand.

[16] Dimitrova, V. (2003). StyLE-OLM: Interactive Open Learner Modelling. International Journal of Artificial Intelligence in Education 13(1), 35-78.

[17] Duan, D., Mitrovic, A., \& Churcher, N. (2010). Evaluating the effectiveness of multiple open student models in EERtutor. In S. L. e. a. Wong (Ed.), International conference on computers in education, Asia-Pacific Society for Computers in Education, 86-88.

[18] Durall, E., \& Gros, B. (2014). Learning analytics as a metacognitive tool. Proceedings of 6th International Conference on Computer Supported Education (CSEDU), 380-384.

[19] Duval, E. (2011). Attention please!: Learning analytics for visualization and recommendation. Proceedings of the $1 \mathrm{st}$ international conference on learning analytics and knowledge, ACM, NY, USA, 9-17. DOI: $10.1145 / 2090116.2090118$

[20] Dyckhoff, A. L., Zielke, D., Bültmann, M., Chatti, M. A., \& Schroeder, U. (2012). Design and implementation of a learning analytics toolkit for teachers. Educational Technology \& Society, 15(3), 58-76. 
[21] Ferguson, R., \& Buckingham Shum, S. (2012). Social learning analytics: Five approaches. Proceedings of the 2nd International Conference on Learning Analytics and Knowledge, 23-33. DOI: 10.1145/2330601.2330616

[22] Gašević, D., Dawson, S., \& Siemens, G. (2015). Let's not forget: Learning analytics are about learning. Techtrends, 59(1), 64-71. DOI: $10.1007 / \mathrm{s} 11528-014-0822-\mathrm{x}$

[23] Jacovina, M. E., Snow, E. L., Allen, L. K., Roscoe, R. D., Weston, J. L., Dai, J., et al. (2015). How to visualize success: Presenting complex data in a writing strategy tutor. In C. Romero, \& M. Pechenizkiy (eds.), Proceedings of 8th international conference on educational data mining.

[24] Kay, J. (1997). Learner know thyself: Student models to give learner control and responsibility. In Z. Halin, T. Ottomann \& Z. Razak (Eds.), Proceedings of international conference on computers in education AACE, 17-24.

[25] Keim, D. A., Kohlhammer, J., Mansmann, F., May, T., \& Wanner, F. (2010). Introduction. In D. A. Keim, J. Kohlhammer, G. Ellis \& F. Mansmann (Eds.), Mastering the information age: Solving problems with visual analytics, Goslar, Germany: Eurographics Association, 1-6.

[26] Kerly, A. \& Bull, S. (2008). Children's Interactions with Inspectable and Negotiated Learner Models, in B.P. Woolf, E. Aimeur, R. Nkambou \& S. Lajoie (eds), Intelligent Tutoring Systems: 9th International Conference, SpringerVerlag, Berlin Heidelberg, 132-141. DOI: 10.1007/978-3540-69132-7_18

[27] Leony, D., Pardo, A., de la Fuente Valentín, Luis, de Castro, D. S., \& Kloos, C. D. (2012). GLASS: A learning analytics visualization tool. Proceedings of the 2nd International Conference on Learning Analytics and Knowledge, pp. 162163. DOI: $10.1145 / 2330601.2330642$

[28] Long, Y., \& Aleven, V. (2013). Supporting students' selfregulated learning with an open learner model in a linear equation tutor. Artificial Intelligence in Education, pp. 219228. DOI: $10.1007 / 978-3-642-39112-5 \_23$

[29] Mabbott, A. \& Bull, S. (2006). Student Preferences for Editing, Persuading and Negotiating the Open Learner Model, in M. Ikeda, K. Ashley \& TW. Chan (eds), Intelligent Tutoring Systems, Springer-Verlag, Berlin Heidelberg, 481490. DOI: $10.1007 / 1177430348$

[30] Mabbott, A. and Bull, S. (2004). Alternative Views on Knowledge: Presentation of Open Learner Models, in J.C. Lester, R.M. Vicari \& F. Paraguacu (eds), 7th International Conference of Intelligent Tutoring Systems, Springer-Verlag, Berlin Heidelberg, 689-698. DOI: 10.1007/978-3-540-301394_65

[31] Mathews, M., Mitrovic, A., Lin, B., Holland, J., \& Churcher, N. (2012). Do your eyes give it away? Using eye tracking data to understand students' attitudes towards open student model representations. Intelligent Tutoring Systems, 422427. DOI: $10.1007 / 978-3-642-30950-2 \_54$

[32] Mazzola, L., Mazza, R. (2010). GVIS: A Facility for Adaptively Mashing Up and Presenting Open Learner Models, in M. Wolpers, P.A. Kirschner, M. Scheffel, S. Lindstaedt \& V. Dimitrova (eds), EC-TEL 2010, SpringerVerlag, Berlin Heidelberg, 554-559. DOI: 10.1007/978-3642-16020-2_53
[33] Mitrovic, A. \& Martin, B. (2007). Evaluating the Effect of Open Student Models on Self-Assessment. Int. Journal of Artificial Intelligence in Education 17(2), 121-144.

[34] Morales, R., Van Labeke, N., Brna, P. \& Chan, M.E. (2009). Open Learner Modelling as the Keystone of the Next generation of Adaptive Learning Environments. In C. Mourlas \& P. Germanakos (eds), Intelligent User Interfaces, Information Science Reference, ICI Global, London, 288312. DOI: 10.4018/978-1-60566-032-5.ch014

[35] Nielsen, J. (2001). First Rule of Usability? Don't Listen to Users, Nielsen Norman Group, nngroup.com/articles/firstrule-of-usability-dont-listen-to-users (accessed 4/2/2016).

[36] Park, Y., \& Jo, I. (2015). Development of the learning analytics dashboard to support students' learning performance. Journal of Universal Computer Science, 21(1), 110-133.

[37] Pérez-Marín, D., Alfonseca, E., Rodríguez, P., \& PascualNieto, I. (2007). A study on the possibility of automatically estimating the confidence value of students' knowledge in generated conceptual models. Journal of Computers, 2(5), 17-26. DOI: $10.4304 /$ jep.2.5.17-26

[38] Santos, J. L., Govaerts, S., Verbert, K., \& Duval, E. (2012). Goal-oriented visualizations of activity tracking: A case study with engineering students. Proceedings of the 2nd International Conference on Learning Analytics and Knowledge, 143-152. DOI: 10.1145/2330601.2330639

[39] Sek, Y. W., Deng, H., \& McKay, E. (2014). Investigating learner preferences in an open learner model (OLM) program: A Malaysian case study. ACIS.

[40] Tchetagni, J., Nkambou, R. \& Bourdeau, J. (2007). Explicit Reflection in Prolog Tutor, Int. Journal of Artificial Intelligence in Education 17(2), 169-215.

[41] Tervakari, A., Silius, K., Koro, J., Paukkeri, J., \& Pirttila, O. (2014). Usefulness of information visualizations based on educational data. IEEE Global Engineering Education Conference (EDUCON), 142-151. DOI: 10.1109/educon.2014.6826081

[42] Thomson, D. \& Mitrovic, A. (2010). Preliminary Evaluation of a Negotiable Student Model in a Constraint-Based ITS, Research and Practice in Technology Enhanced Learning 5(1), 19-33. DOI: 10.1142/s1793206810000797

[43] Verbert, K., Govaerts, S., Duval, E., Santos, J.L., Van Assche, F., Parra, G. \& Klerkx, J. (2014). Learning Dashboards: an Overview and Future Research Opportunities, Personal and Ubiquitous Computing 18, 1499. 1514. DOI: $10.1007 / \mathrm{s} 00779-013-0751-2$

[44] Vozniuk, A., Govaerts, S., \& Gillet, D. (2013). Towards portable learning analytics dashboards. 13th International Conference on Advanced Learning Technologies (ICALT), IEEE, 412-416. DOI: 10.1109/icalt.2013.126

[45] Weber, G., \& Brusilovsky, P. (2001). ELM-ART: An adaptive versatile system for web-based instruction. International Journal of Artificial Intelligence in Education $12,351-384$.

[46] Woolf, B.P. (2010). Chapter 13: Student Modeling, in R. Nkambou, J. Bourdeau \& R. Mizoguchi (eds), Advances in Intelligent Tutoring Systems, Springer-Verlag, Berlin Heidelberg, 267-279. 